\title{
Challenges of Knowledge and Information Management during New Product Introduction: Experiences from a Finnish Multinational Company
}

\author{
Eeva Järvenpää, Miia-Johanna Kopra, and Minna Lanz \\ Tampere University of Technology, Department of Mechanical \\ Engineering and Industrial Systems, Tampere, Finland
}

eeva.jarvenpaa@tut.fi; miia-johanna.kopra@tut.fi; minna.lanz@tut.fi

\begin{abstract}
Efficient knowledge and information management is essential for companies to prosper in the rapidly changing global environment. This article presents challenges of a large Finnish multinational company relating to their current knowledge and information management practices and systems. The focus is on New Product Introduction (NPI) process. The study is based on interviews and facilitated workshops in the Research and Development (R\&D) and Production departments. Furthermore, the identified challenges are reflected to the findings presented in knowledge and information management literature.

The results gained from the company case study were well in line with the findings in the literature. Three main topics, which can be generalized to cause challenges for knowledge and information management in most companies, were recognized: 1) Issues related to human behavior, individual characteristics and capabilities, different backgrounds, and professional vocabulary; 2) Codifying tacit knowledge into explicit information, which can be saved to company information system; 3) Lack of interoperability between different information systems.

The study provides the management of the case company, and other similar organizations, focus points while seeking for better knowledge and information management. From a scientific perspective, the main contribution of this article is to give practical examples of how the theoretical findings presented in literature manifest themselves in real industrial practices.
\end{abstract}

Keywords: knowledge management, information management, knowledge creation, knowledge sharing, information sharing, information flows, case study

(CC BY-NC 4.0) This article is licensed to you under a Creative Commons AttributionNonCommercial 4.0 International License. When you copy and redistribute this paper in full or in part, you need to provide proper attribution to it to ensure that others can later locate this work (and to ensure that others do not accuse you of plagiarism). You may (and we encourage you to) adapt, remix, transform, and build upon the material for any non-commercial purposes. This license does not permit you to use this material for commercial purposes.

\section{Introduction}

The ever shortening product lifecycles and rapidly changing customer requirements lead the modern manufacturing companies to practice a concurrent engineering (CE) paradigm. To succeed in CE, efficient communication between individuals from different departments in-house and within the production network is a must. In large production organizations, design and modelling of complex 
products, their production processes and systems is typically done by multi-disciplinary, often multicultural and geographically distributed design teams. The required cooperation and communication between the teams and each individual member of the team is heterogeneous due to the different IT systems (Information Technology) and platforms, as well as, each member's different specializations, tasks and backgrounds. As stated by Haldin-Herrgard (2000), sharing of all forms of knowledge requires a commonly understood terminology. However, usually each team or individual member of a team is specialized in solving problems related to a given phase of the product's lifecycle, which makes the work content and thus also the used terminology different. Therefore, the communication and sharing of knowledge and information may be challenging. This heterogeneity affects both the communication between the individuals and their interaction with the information systems. Furthermore, the more distance the individuals have from each other's practice, the more difficult it is to communicate the knowledge they use (Crossan, Lane, \& White, 1999).

Knowledge sharing can be managed by focusing either on the social dynamics between the members in the organization or management interventions (van den Hooff \& Huysman, 2009). Many formal knowledge sharing practices depend on the information systems offering support on information acquisition, organization, storage, retrieval, search, presentation, distribution, and reproduction. The technology often removes the temporal physical and social distance barriers by improving the knowledge sharing process, and locating knowledge carriers and seekers (Thierauf, 2001). On the other hand, also the IT systems suffer from lack of common vocabulary. For example, in product development, for each product several different product models, related to different phases or aspects of its lifecycle, are created and used. Therefore, vast amount of different types of information and CAx-systems (Computer Aided X) are used throughout the whole product lifecycle. As the different systems usually rely on different data structures, this leads to problems with their interoperability. It affects negatively to the transparency between different design teams and departments within an organization and its network.

This article will present a practical case study of the knowledge and information management issues in a large Finnish globally operating company. Knowledge management here refers to the process of creating, sharing, transferring and using of collective knowledge in an organization to help the organization compete (von Krogh 1998). Knowledge always includes the tacit dimension and cannot thus be saved to the IT systems as such (Subashini, 2010; Walsham, 2001). Therefore, the terms information and information management are used when discussing about creating, sharing, transferring, and using content in written documents, emails, information systems, and databases. The study concentrated on New Product Introduction (NPI) process, which consists of the phases from product development and detailed design until production ramp up of the newly designed product. The focus was especially on the interface between product design and production. The focal aim in the practical case study conducted in the company was to recognize the weak points in the current knowledge and information management practices and solutions, in order to be able to improve the organization's knowledge and information management and transparency. In this article the practical findings from the case company are mirrored against the findings from the theoretical knowledge and information management literature. Both technical and social aspects are discussed.

The article is organized as follows. In the next section, the theoretical background around knowledge and information management is discussed. The paper then describes the research objectives and methods, followed by a presentation of the main results of the case study in the company concentrating on the identified challenges with the current knowledge management practices, tools and information flows. In the fifth section, the results are discussed and mirrored against relevant literature, while the final conclusions are presented in the final section. 


\section{Theoretical Background}

\section{Concept of Knowledge}

In the knowledge management literature, three levels of knowledge - data, information, and knowledge - are commonly distinguished. According to Awad and Ghaziri (2004), data is defined as unstructured facts, which in IT terms are usually considered as just raw bits, bytes, or characters. Information is structured data and attributes which can be communicated, but which may only have meaning locked inside a proprietary software. Knowledge is seen as information that has meaning in more than only one software and can be used to achieve some results (Awad $\&$ Ghaziri, 2004). Moving on from an IT-oriented definition to a more human-centric definition, it has been stated that when information is understood and its suitability to other situations is compared, it becomes knowledge (Bierly, Kessler, \& Christensen, 2000; Bratianu \& Orzea, 2010; Davenport \& Prusak, 1998). According to Jashapara (2011), knowledge can be considered as actionable information, which allows people to make better decision and to provide effective input to dialogue and creativity in the organization. Knowledge consists of information, experience, mental models, relations, values, principles, beliefs, and commitments (Bratianu \& Orzea, 2010) and technology, know-how, and skills (Nonaka, Toyama, \& Konno, 2000).

A number of authors, however, disagree with the presented concept hierarchy. Tuomi (1999a) pointed out that these traditional three level definitions treat knowledge as a higher level of information and data. He claims that data emerges only after information, and that information emerges only after there already exist knowledge. Nissen (2002) argued that from the knowledge seeker's point of view, data is put into context to create information, and actionable information, becomes knowledge. Nevertheless, from the author's perspective, knowledge is needed to create information, which in turn, is needed to create data.

\section{Tacit and Explicit Knowledge}

Since the seminal works of Polanyi $(1966,1969 a, 1969 b)$ there has been a strong interest in the area of knowledge management research to divide the knowledge into tacit and explicit knowledge. By the definition of Nonaka and von Krogh (2009), explicit knowledge is knowledge that is uttered, formulated in sentences or captured in drawings, and it has universal character supporting the capacity to act across contexts. Understanding explicit knowledge requires a certain level of academic knowledge or understanding, which is gained through formal education or structured study (E. A. Smith, 2001). Tacit knowledge, in contrast, is knowledge that is unarticulated and tied to the senses, movement skills, physical experiences, intuition, or implicit rules of thumb (Nonaka \& von Krogh, 2009). Hildreth and Kimble (2002) stated that tacit knowledge cannot be represented in language, writing, or tools.

It is hard, if not even impossible, to distinguish conceptually between explicit and tacit knowledge, because they are not separate and discrete in practice (Lam, 2000). Even Polanyi didn't want to separate these two types of knowledge, but stated that explicit knowledge is always grounded in tacit knowledge. Tacit knowledge is needed to understand explicit knowledge (Polanyi, 1966, 1969a), Later on it has been agreed by researchers, that tacit and explicit knowledge dynamically interact with each other in creative activities by individuals and groups allowing the creation of new knowledge (Alavi \& Leidner, 2001; Nonaka \& Lewin, 1994). Explicit knowledge without the tacit insight quickly loses its meaning (Subashini, 2010).

\section{Knowledge Creation, Sharing, and Transfer}

Knowledge is created in social interaction (Nonaka, 1994). The values and beliefs of the knower determine what he sees, absorbs, and concludes from the observation (Davenport \& Prusak, 
1998), thus making the process of knowledge creation unpredictable (von Krogh, Ichijo, \& Nonaka, 2000). Due to its personalized nature, knowledge needs to be expressed for it to be useful for the others (Alavi \& Leidner, 2001).

Knowledge creation in organizations is influenced by factors such as organizational culture, leadership, organizational structures and incentives systems, which provide a social context for, enable, or constrain the process where people with different knowledge and interests interact (Nonaka \& Konno, 1998; von Krogh, 1998). The empirical work by multiple researchers, reviewed by Nonaka and von Krogh (2009), has shown that organizational knowledge creation is very sensitive to social context, such as the organization of processes (Dyck, Starke, Mischke, \& Mauws, 2005), timing of activities (Massey \& Montoya-Weiss, 2006), physical proximity of people (McFadyen \& Cannella, 2005), and people's use of technology (Chou \& He, 2004).

Knowledge sharing refers to the activities through which knowledge is exchanged among the individuals, groups, or organizations. The goal of knowledge sharing is either to create new knowledge by differently combining existing knowledge or to become better at exploiting existing knowledge (Christensen, 2007). Shared knowledge can be both explicit and tacit. Tacit knowledge cannot be taught. Learning tacit knowledge requires active contribution of the learner and the learning process takes time (Haldin-Herrgard, 2000).

van den Hooff and Huysman (2009) emphasized that there are two approaches in managing knowledge sharing in companies: emergent and engineering approaches. The emergent approach focuses on the social dynamics between the members in the organization indicating that sharing of knowledge cannot be forced, but it results from a shared intrinsic motivation to share, gained by the donor socially embedded. Motivation for creating and sharing knowledge is based on the considerations of personal benefit, community related expectations, and normative beliefs (Ardichvili, 2008). The engineering approach, on the other hand, focuses on the management interventions to facilitate knowledge sharing and transfer. The central assumption in this approach is that organization's management can play a role in knowledge sharing by stimulating and creating an environment and conditions for the emergent process. (van den Hooff \& Huysman, 2009)

Bartol and Srivastava (2002) identified four major mechanisms for the individuals to share their knowledge in the organizations. The individuals contribute their ideas, information, and expertise to the organizational databases. Sharing knowledge in formal interactions within, or across, the teams or the work unit, could take place when the teams or the departments hold their periodic meetings. Informal knowledge sharing includes informal coffee table or water cooler chats. This communication is usually not recorded, and the contributions of knowledge are based on the premise of social exchange. Another option is to share knowledge within information communities, in which the individuals can communicate on topics of their interest in a non-routine, personal and unstructured way. (Bartol \& Srivastava, 2002)

Many authors (e.g., Nonaka, 1994) emphasize that tacit knowledge needs to be made explicit for sharing, thus making codification an essential step in leveraging the value of knowledge in the organization. Knowledge codification refers to the process of knowledge being transformed into information, a form of message or sets of identifiable rules and relationships, which can be transmitted (Kogut \& Zander, 1992). Knowledge codification allows knowledge to be accessed and used by others sometime in the future, and it is not dependent on personal networking (Newell \& Edelman, 2008). Converting knowledge into explicit information includes explaining one's own experiences and viewpoints in a way that is understandable to others. Polanyi (1969b) discussed sense-giving and sense-reading activities. During the sense-giving activity, the knowledge is turned into explicit information by the knowledge holder, while during the sensereading activity knowledge is again created from the explicit information by the knowledge re- 
ceiver. As Tuomi (1999b) stated, to understand the knowledge similarly, the original articulator and the sense-reader have to have overlapping meaning structure. Nonaka et al. (2000) saw that a cross-functional group improves the possibilities to articulate tacit knowledge into explicit concepts. However, collaboration in such a group can be difficult, because each profession has its own language, terminology, beliefs, approaches to learning, mechanisms for information exchange, goals, and reward structure (Edmondson \& Nembhard, 2009). Also, more experience and deeper knowledge leads to high tacitness of knowledge, which in turn leads to the greater difficulties to articulate knowledge (Crossan et al., 1999).

Walsham (2001) stated that when computers are used to support collaboration, collective sensemaking becomes a problem. It may be the case, for instance, that people using the system lack the shared symbols such as the professional language, that their expectations and practices differ, or that they have different cultural norms and behavior. Walsham noted that in contrast to large data warehouse systems, personal interaction between individuals in a community with common symbols, such as specialist language and job purpose, facilitate the sense-giving and sense-reading processes in a way which supports the knowledge sharing. He also argued that the difficulties of coping with the ways of working, methods of describing this, and taken-for-granted assumptions of people in other communities are likely to be exacerbated where electronic media are used, because it eliminates the bodily cues and dynamic interpersonal interaction of face-to-face contact. (Walsham, 2001)

Knowledge transfer means identifying explicit knowledge, and then transferring and applying this knowledge to solve specific tasks better, faster, and cheaper than they would otherwise have been solved (H. A. Smith, McKeen, \& Singh, 2007). Knowledge transfer matters most when knowledge creation and knowledge utilization are separated in time and place (Jashapara, 2011). Even in project-based organizations, there seldom are any organizational mechanisms for the knowledge acquired in one project to be transferred and used by the other projects (Prencipe \& Tell, 2001). Knowledge from project to project flows through direct and detoured transfers (Jeon, 2009). The mediums of direct transfers are mainly employees, who directly move to the next project. Knowledge repositories can function either has a knowledge losing hole or as a value adding mechanism.

\section{Information in Design Systems}

Based on the theory presented in the previous sections, knowledge cannot be saved to the IT systems as such. Walsham (2001) pointed out that all databases, on-line data sources, or contents of e-mails are explicit knowledge (information) that should not be confused with much deeper tacit knowledge which has created them in the first place. Furthermore, according to Tuomi (1999a), when articulated explicit information is stored in computer memory for automatic manipulation, the meaning of the information must be represented. In database systems, information has to be split into bits and bytes and the data gets detached from the meaning. The computer does not have access to the meaning of the content it is processing. In other words, when the information has been put to a computer processable form, it has become data. (Tuomi 1999a)

In a large-scale company, there can be up to hundreds of different design support and other IT systems, different versions and ad hoc applications, which are used to create the information of product, processes, and production systems. Usually, these systems use their proprietary data structures and vaguely described semantics. This leads to challenges in sharing information between different systems since commonly these are not truly able to share information beyond geometric visualizations (Lanz, 2010). For each product several different product models, related to different phases or aspects of its lifecycle, are created and used. Typically, the model related to a given lifecycle phase is prepared by a dedicated CAx-system and can be modified or further developed only by identical or compatible systems, capable of reading the models in their initial 
format. This means that the models live only inside their authoring systems and are otherwise largely useless. The design process is thus strongly determined by the CAx-systems where the data models are created even though the design of the models should be the main interest.

The final modelling of product or process is often achieved by integration of models created in these different CAx-systems by different design teams. Communication between the teams and information systems used is usually handled by data exchange. Data exchange refers to all the actions that have to be performed (e.g., physical transfer of the model and possible conversion) in order to make a model created or existing on a given platform work on another platform (Avgoustinov, 2007). As a result, the integration of models involves a great deal of data processing, the largest part of which is conversion from one format/language into another. Despite the numerous standards on the information exchange, communication among the partners and integration of the respective models often encounter problems. During the format conversions a great deal of data is often lost. A lot of effort, and thus money, is used to resolve such kind of interoperability issues in companies (Ray \& Jones, 2006).

It also has to be noted that the current design systems are unable to store design knowledge and much less the design intent (Lanz, 2010). The meta information of the design is often only the 3D geometry with little extra such as creation and modification dates, tolerance information, materials and possibly connections to the (main)assembly. Without the meaning, the models become shallow since they lose the connection to the designer's motivation or reasons to choose different design parameters. In order to make sense of the document or model, a lot of contextual knowledge is needed. The company databases and Product Data Management (PDM) systems contain partly structured information, but mainly it is unstructured without relations between concepts. Content in the information systems is often syntactic. It is human, but not machine readable. This means that computers cannot reason with it. Also for human, it requires knowledge of the context where it was created in order to understand and reason with it properly.

Based on the above discussion, it can be said that knowledge cannot be saved to traditional information systems. Only its explicit parts - information and data - can be formalized and saved. However, emerging semantic information systems utilizing ontologies aim to overcome this drawback by allowing at least some level of knowledge to be stored and shared (Ray \& Jones, 2006). The vision of the Semantic Web is to augment the syntactic web so that resources are more easily interpreted by programs. The enhancements will be achieved through semantic markups which are machine-understandable annotations associated with Web resources (Staab \& Studer, 2009). Ontologies offer the possibility to represent formal semantics, efficiently model and manage distributed data, ease the interoperability of different applications, and exploit generic tools that can infer from and reason about an ontology. Moreover, ontologies allow integrating fragmented data models into a unique model without losing the notation and style of the individual ones. (Hepp, Leenheer, de Moor, \& Sure, 2007)

\section{Description of Research}

\section{Research Objectives and Scope}

The aim of this article is twofold:

1. to present the main findings related to the knowledge and information management challenges, which hinder efficient knowledge and information creation and sharing, information flows, and transparency in the case company; 
2. to compare these findings to the existing knowledge management literature, and to illustrate how the theoretical findings from the literature are reflected to actual industrial practices within the case company.

The research was initiated by the case company, which is a large Finnish globally operating industrial corporation. The company has research, design, and manufacturing operations in-house. They had identified a need to improve transparency and information flows during the New Product Introduction (NPI) phase between the R\&D (Research and Development) and Production Department, as well as, between different teams and individuals within these departments. The current process graphs were not up-to-date, and no attempts to model the information flows between different teams and information systems had been made before. The main objective of the case study, conducted in the company, was to make a current state analysis of the information and knowledge management and sharing practices and tools, information flows, and associated challenges. This analysis was intended to serve as a background for the company's internal development activities. The initial scope and objective of the practical case study was to improve the information and knowledge management and transparency from an IT perspective, as the IT tools were considered as the biggest cause of issues in the case company. However, the case study revealed many issues related to human behavior, interaction, and social aspects, which led to the extension of the scope during the analysis phase (please see further details in the next section).

\section{Research Method and Process}

The company provided two persons from the Mechanics Design Department to facilitate and supervise the current state analysis. One person was from the management level, while the other person was a mechanical designer. Both were involved during the current state analysis planning, and reviewing and extending the analysis results.

The information collection for the current state analysis was mainly carried out by interviewing critical persons in the NPI process within the case company and among its sub-contractors. Seven persons from the case organization were interviewed. The persons were selected partially based on the evaluation of the facilitators and partially by using snowball sampling. This means that the interviewed persons named other persons who they thought should be interviewed. From R\&D Department the interviewed persons were R\&D Manager, Mechanics Designer, and two Product Managers from prototype production. From the Production Department the following representatives were interviewed: Production Technology Manager and two Industrial Engineers. In addition, four sub-contractor representatives from two companies were interviewed. These subcontractors manufacture tools and jigs for the target company's production. Altogether, eleven persons were interviewed. The study concentrated mainly on products which were both designed and manufactured in Finland. Even though the concentration was on domestic operations, each of the interviewed persons had a long experience on working in international projects, which was reflected to the interview results. Thus, the amount of the interviewees was considered sufficient.

Semi-structured open-ended interview was selected as the interviewing method, as it allows a lot of information to be collected and analyzed in a qualitative manner. The method allows freedom to ask further questions, explain details relating to the questions, adjust the order of the questions, and select the used wording based on the person who is being interviewed. Also the existing process descriptions, relating to the product development and production ramp-up phases, were studied. The purpose was to detect any inconsistencies between the official processes and the actual practice.

The research presented in this paper was conducted in two cycles, as shown in Figure 1. The practical case study started with the initial assumption that the information transparency and flows can be improved by concentrating on studying the IT systems and how people interact with 
them. Thus, the authors started with a literature review focusing on IT tools in the product development and production ramp-up phases. After gaining sufficient pre-understanding regarding the topic, the actual current state analysis of the company started by formulating the interview questions. Even though the initial literature review concentrated only on IT systems and formats, the researchers and facilitators had the understanding that human-related aspects cannot be completely neglected from the interviews. Use of IT systems is enabled by humans and successful use of technology or applications is always due to interaction between people and the systems (Ritter, Baxter, \& Churchill, 2014). Therefore, during the current state analysis, the knowledge and information flows were observed on three levels: between humans, information systems, and formats. The viewpoint was still very much IT-oriented.
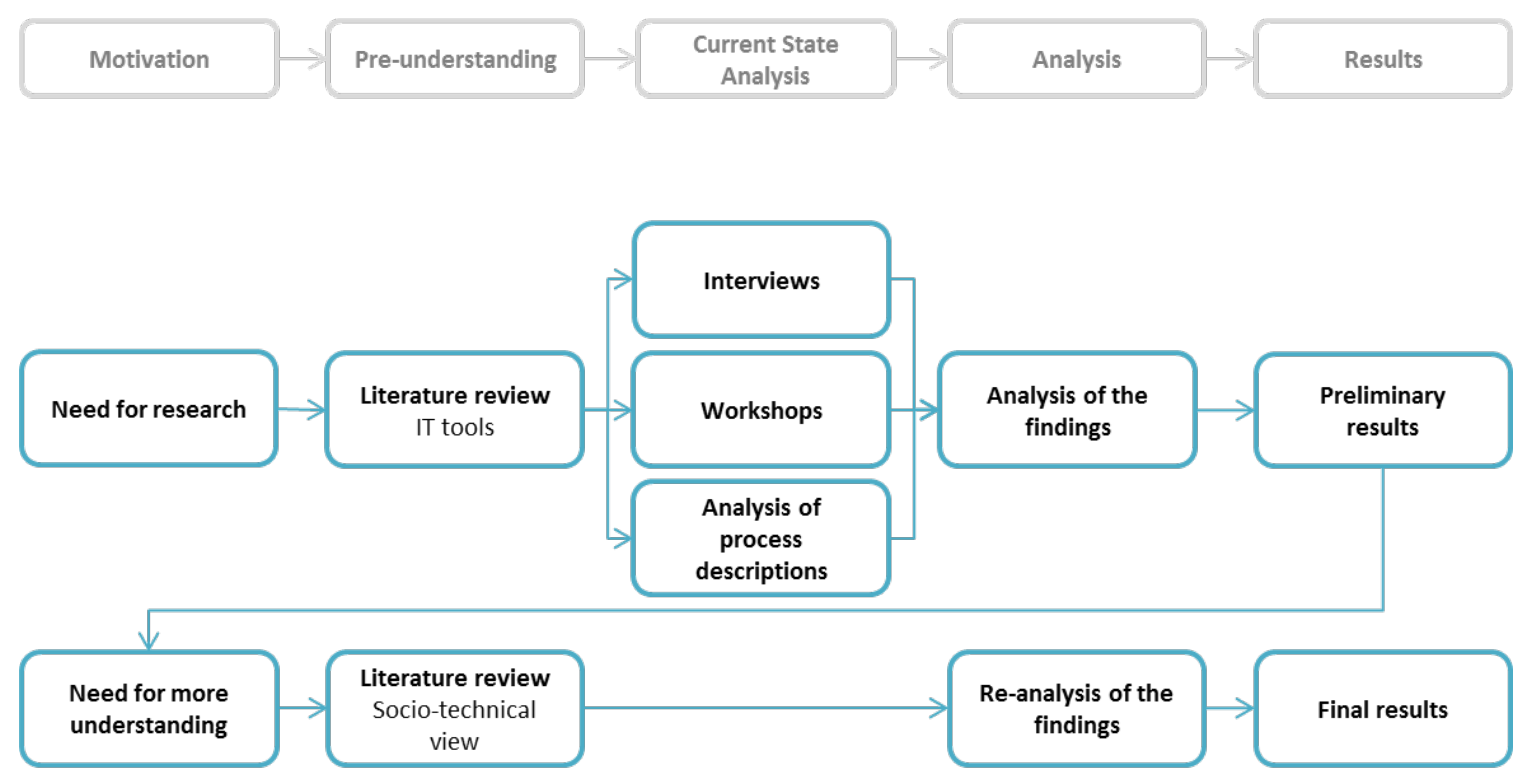

Figure 1: Map of the research process.

The interview questions were prepared to go through the relevant areas on three levels:

- The human level viewed the knowledge and information flows between designers, engineers, and other members in the organization during the NPI process and how people utilize different IT systems during this process.

- The system level viewed the information flows between different information systems and identified what kinds of models and documents are created, exchanged, and shared between different IT systems.

- The format level viewed about what actually can be saved into the utilized IT systems and what can be transferred between them on a parameter level.

The focus of the interview questions was on knowledge and information flows in R\&D and between R\&D and Production Departments. The topics listed in Table 1 were covered with the aim to map the knowledge and information inputs, outputs, sources, and receivers, and to identify the current practices and challenges within information and knowledge management. As the focus was IT-oriented, the main emphasis was placed on information rather than knowledge flows. 
Table 1: Topics of the interviews and example questions related to each topic

\begin{tabular}{|l|l|}
\hline Question topic & Example questions \\
\hline $\begin{array}{l}\text { Information and knowledge } \\
\text { inputs required and outputs } \\
\text { created by the individuals and } \\
\text { teams }\end{array}$ & $\begin{array}{l}\text { "What information and knowledge you or your team create as a part of } \\
\text { your task(s)?" }\end{array}$ \\
\hline $\begin{array}{l}\text { Main information or } \\
\text { teams in order to be able to complete your task(s)?" } \\
\text { recognized by the individuals } \\
\text { and teams, communication } \\
\text { practices }\end{array}$ & $\begin{array}{l}\text { "Who creates the information or knowledge you need?", "From where you } \\
\text { "Who needs the information or knowledge that you create?", "How do } \\
\text { you deliver that information or knowledge?" }\end{array}$ \\
\hline $\begin{array}{l}\text { Information systems used in } \\
\text { different product lifecycle } \\
\text { phases }\end{array}$ & $\begin{array}{l}\text { "What information systems do you use in your different tasks?" } \\
\text { "What information do you create or look for with/from these information } \\
\text { systems?" }\end{array}$ \\
\hline $\begin{array}{l}\text { Information models, their } \\
\text { content and used formats }\end{array}$ & $\begin{array}{l}\text { "What information is saved to the models and files that you create?", "In } \\
\text { which format the information is saved?" }\end{array}$ \\
\hline $\begin{array}{l}\text { Information transfer between } \\
\text { the different information } \\
\text { systems }\end{array}$ & $\begin{array}{l}\text { "How easily the information saved in one system can be viewed or ma- } \\
\text { nipulated in other system?" } \\
\text { "Do you often encounter problems with different formats and their in- } \\
\text { teroperability?", "What kind of problems?" }\end{array}$ \\
\hline $\begin{array}{l}\text { Main challenges in } \\
\text { knowledge and information } \\
\text { sharing and transfer }\end{array}$ & $\begin{array}{l}\text { "What would you say are the main challenges you encounter with } \\
\text { knowledge and information sharing and transfer in your everyday work?" }\end{array}$ \\
\hline
\end{tabular}

After the interview process, the results, including the drawn graphs of the information flows between the utilized IT systems, were revised in two full-day workshops, where wider group of individuals from the case company were invited. Altogether 14 persons took part in these workshops, three of them being same individuals who took part in the interviews, others being their colleagues from R\&D and Production departments. In these workshops the information flow graphs were reviewed and filled with the missing IT tools and information flows. Furthermore, the challenges recognized during the interviews were discussed and the participants were given the opportunity to express their opinions on the results and to bring in new information. The results of the workshop were included into the current state analysis findings.

The first cycle ended by analyzing the findings from the current state analysis and presenting the results to the company. The results indicated that to improve the information and knowledge management on the organizational level, the focus on IT aspects was insufficient and the research needed refocusing in the analysis phase. The interviewees had brought out many things related to psychological, behavioural, and social aspects related to knowledge management. The company was satisfied with the results from the first cycle, i.e., the current state analysis, and continued with their internal development. In order to understand better the results of the interviews from the scientific perspective, the authors initiated the second research cycle. An additional literature review and analysis was made with a focus on knowledge management and socio-technical view on the topic. The overall results are presented in this article. 


\section{Identified Knowledge and Information Management Challenges}

This section will review the main results of the practical case study and interviews conducted in the case company. The main emphasis is placed on the identified challenges related to knowledge and information management. The results are divided into two categories, social and technical challenges, and are summarized in Figure 2.

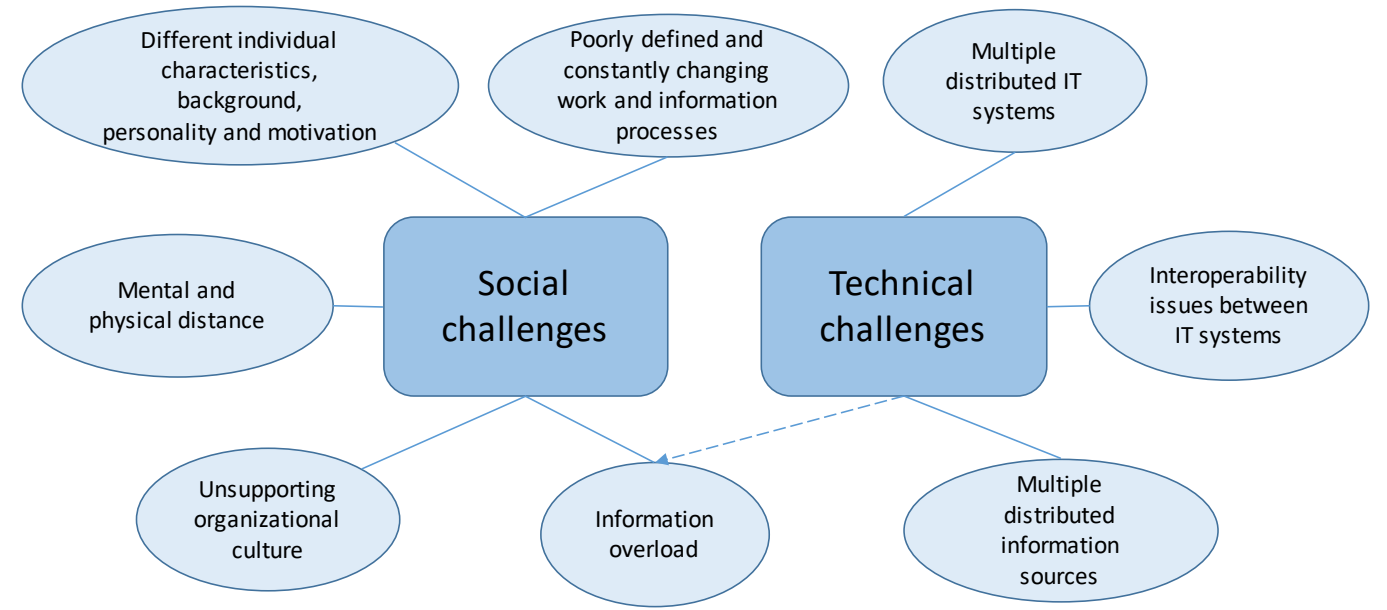

Figure 2: Main themes of the identified knowledge and information management challenges in the case company.

\section{Social Challenges}

\section{Individual characteristics, background, and mental and physical distance}

Based on the interviews, it was noted that the personality and background of individuals affects greatly on the communication, both in face-to-face and how the information systems are utilized. Different individuals had very different ways to do and understand things, different knowledge, and interests, which led easily to misunderstandings in knowledge and information sharing, transfer, and cooperation. This issue was directly mentioned by many of the interviewees with statements such as: "You have to be really specific on what you mean, when communicating with persons you don't work with every day. We have our own language here" (stated by Product Manager). Based on the given answers, the teams in the same department were capable to easily share knowledge with each other in an effective way. This means that the receiver was able to understand the knowledge as intended and to use it for further activities. However, when the team boundaries were crossed, the knowledge sharing became more difficult. This was not only because of different specialist language or job purpose, but also because of often contradictory and competing work goals. Each individual had a different image of the overall NPI process and what was important, depending on one's own job description, Key Performance Indicators, interests, and background. For example, the R\&D Manager stated: "This is a huge company, where everybody concentrates on their own small task area. They don't always understand how others are affected by their work or who could benefit from their input."

The communication problems were clearly visible also with the sub-contractors. As the Product Manager stated: "Sub-contractor (or other instance) may have never heard the term or acronym that we use, or may have understood it totally differently as intended". Nevertheless, as stated by 
the Mechanic Designer who interacts a lot with the sub-contractors during the design phase, with those companies with whom they had been co-operating for years, communication by only emails and short specification lists was enough to produce results in good quality. This was due to the "common language" they had built during the long-lasting co-operation. However, information security and trust issues relating to the communication in the production network, especially in global level, were clearly recognized. Even though the access to critical information could be restricted by access rights, the case company still felt unsecure to share, e.g., product models with their global suppliers.

The physical spaces in the organization impact on how the organizational members interact. It was mentioned that individuals sharing the same office room were much more likely to share knowledge and information than people working in further away from each other. This was obviously due to the social face-to-face situations they encountered every day, which gave a natural basis for the communication. However, the physical proximity doesn't always help, since also chemistry between the individuals and teams and personality affect greatly to the interaction. This was highlighted by the Technology Manager who said: "It is all about the people. Of course the co-operation is generally more difficult if the distances are long, but more it depends on the person and his/her openness and skills. With some people the communication works fine despite the long distances, with some people it doesn't work even though they would be sitting next to you." Similar statement was given by one of the sub-contractor representatives who said: "The success of the project depend on who is the contact person in the customer side. When we hear the name, we can forecast how the project will go."

The Product Manager mentioned that sometimes when working in international projects, e.g., if the manufacturing is done abroad, the language barriers become an issue. "Sometimes the manufacturing site knows there is an issue in the product design regarding its assemblability, but they cannot explain this understandably to the design team. This inevitably causes troubles when the product is taken into production."

\section{Information overload and different ways to use IT systems}

There was a remarkable contradiction between the desire to make knowledge explicit and the motivation in practice to manage huge information repositories and databases. The interviewed persons did not specifically highlight the difficulty of turning knowledge into explicit information but this conversion is usually not fully unproblematic, as discussed in the literature review. It seems that the individuals were able to formulate their tacit knowledge into explicit form, but they had very little motivation to do that. The interviewed persons did not have a specific reason to convert the tacit knowledge to explicit because the company did not reward for such an activity nor punish for discarding it. However, the main cause for the individuals' lack of motivation for converting tacit knowledge into explicit was mentioned as information overload. Many of the interviewees highlighted that, due to the information overload, in some point it becomes impossible to recognize the relevant information and something critical will be missed.

Knowledge codification was seen as a redundant task since nobody would find or re-use the documents anyway, i.e., many IT systems and databases were considered as knowledge losing holes. For example, the Industrial Engineers, who analyze the products based on their assemblability during prototype production stated: "Bad and unsuccessful design solutions, and problems encountered during the prototype production, have been documented properly in the dedicated system, but still the design teams keep on repeating the same mistakes over and over again in further product generations." The Technology Manager mentioned about the same issue and said: "You cannot expect that anybody reads the reports of prototype production. If there is an issue, it is better to have a meeting with designers to discuss about them, rather than expect the designers to check the problem report." 
The previous statements also indicate that even though the information would be saved into the dedicated IT systems and in good case even be flowing automatically between different systems, it doesn't always get the needed attention. Therefore, one has to go to talk with the related person face-to-face. This was mentioned by all the company's interviewees. One practical statement done by the Technology Manager, who works in the interface between product development and prototype production, was that "the documents sent by e-mail should be attached to the mail as an attachment, not as a link. If opening the link requires a password, the documents may be left unopened." This statement reflected also the annoyance that the people had towards having to use so many different IT systems and memorizing the passwords.

Information overload combined with poorly organized document repositories, hindered the effective use and re-use of the created documents in the case company. All the company's internal interviewees complained that it is very hard to find the needed information, or even know that some information exists. Finding information requires very specific knowledge, e.g., a specific project number. One of the Industrial Engineers said: "Even though one would have an access to the correct location on the server, one will nearly never find all the needed information without asking someone." The R\&D Manager put it this way: "We have hundreds of different IT systems and loads of information somewhere. Nobody finds it. Wheel is invented over and over again."

Furthermore, bad usability of the systems was mentioned by all the interviewees. The interviews revealed that many of the used IT systems were considered as annoying because they don't support the current processes in an optimal way. It became also clear that the persons lacked experience and knowledge on how to utilize full potential of the systems. The different ways people use IT systems was recognized as a tremendous challenge for the effective knowledge and information management in the case company. There were, for instance, different views about the importance of certain activities and actions and different professional languages and practices between teams. For example, both of the Industrial Engineers mentioned that everybody doesn't always save the newest information to a dedicated system, but it stays on files on distributed locations. "Sometimes we need to push people to save the information to the system", they said.

In addition, because different people tended to use the systems in a different way and with different experience, the information that could be retrieved from the systems was not always consistent and reliable. The Technology Manager highlighted: "It is up to the individual what kind of results are got by the same analysis tool. In most cases he/she needs to manually fill in the input data. But first he/she needs to find it from somewhere and to evaluate if it is relevant and up-todate." This indicates that a lot of tacit knowledge is needed when using different IT tools.

One big problem that was brought out by all the interviewees related to the notification about the updates and changes affecting to the product models. Information about updates, e.g., to the product design, was not distributed fluently enough, and the users didn't know if they had the newest models or documents in their hands. This problem indicates strongly the splintered information flow, where the information is not connected anywhere. In addition, it indicates that the PDM system and others were not used systematically by everybody. Especially the sub-contractor companies saw this as the biggest issue in the information flow between them and their customer. The information sharing platform used with the sub-contractors didn't support automatic notifications about updates. One of the sub-contractor representatives said: "The contact person from our customer needs to call or send a message to us, when the model has been updated. Sometimes they don't do that. Or they don't even update the model in the platform. Usually we have no idea if we hold the newest versions of the files in our hands or not." 


\section{Unclear processes and weak transparency}

In the case company, the continuous changes in routines were seen as a tremendous problem. The processes were renewed so often that when the teams started to apply them, they were already obsolete and there was no consistency between the processes followed by different teams. As stated by the R\&D Manager: "New process descriptions are made even though the old ones are yet to be implemented." This led even to a certain level of ignorance towards the processes. Product Manager highlighted this by saying: "If no strict checklist on the tasks that should be completed exist, some unpleasant process steps may be neglected. Gradually they get vanished total$l y$, as new personnel don't know of their existence". Also the interfaces between the processes and teams performing those processes were not well defined and documented. This affected negatively to the information flows and transparency.

Due to weak transparency, the interviewed persons tended to have a very narrow image of the overall product process concentrating only on their own tasks. The "big picture" of the overall process was often missing from the individuals. They didn't see how the final result was emerged from the individual decisions during the NPI process. The tacit knowledge of the activities during product creation process, especially their linkages and effects on each other, seemed to remain on the managerial level. On the other hand, according to both the R\&D Manager and Mechanics Designer, the managers rarely have a good knowledge of what actually happens in the designers' offices and on the factory floor. Furthermore, the Technology Manager supported this by saying that: "The higher management doesn't understand the reasons behind the decisions of the design teams. They ask to change the decisions even though the designer teams have analyzed the situation thoroughly and noticed it is impossible."

The effect of social context on the knowledge and information sharing was very clear. Vaguely organized and constantly changing processes caused inability of the teams and individuals to know who is affected by their work and decisions and, on the other hand, what kind of information they needed to provide for others and what kind of input they could expect from other teams and individuals, and from where to find that information. For example, the Industrial Engineers stated that: "You don't always know who is responsible of doing what. The fancy job titles don't tell anything about the job content."

Timing of activities was seen crucial for the knowledge creation and sharing right kind of information with others. Again, because of the unclear processes, the timing of activities was not even close to optimal and therefore many decisions had to be made based on missing information and specifications. Therefore, multiple iteration rounds to fix problems, caused by inadequate information during the decision-making point, had to be taken.

\section{Technical Challenges with Information Management}

\section{Multiple distributed IT systems with weak integration}

During the NPI process, vast amounts of different plans, models, and other documentation is created in different formats. In the case company, the engineering drawings and product models were maintained in a proprietary CAD (Computer Aided Design) system format, whereas the information on materials, surface finishing, packaging, electrical connections, assembly process and sequence, resources, and so on were contained in various dispersed documents and stored in variety of formats, such as .doc, .ppt, .xls, and .pdf.

One problem noticed clearly in the company was that even though the information could be formally represented in one software tool, it couldn't be further distributed to the downstream applications. Even though the phases in NPI process are strongly related and utilize each other's requirements, constraints, and pre-descriptions, the models and documentation created during these 
phases, and their many sub-phases, were hardly connected. As identified during the study, these models and documents contain partly the same information, 3D geometry for example. This led to a great deal of data redundancy. The changes done in the geometry should affect to both of the models. However, in reality, the use of multiple proprietary formats forced the experts to serve as a manual human-machine interface between different systems causing vast amount of manual work and possibility for human errors.

As stated by the Mechanics Designer and the R\&D Manager, a common practice in the company was that after each product's lifecycle phase the different design teams create the models and documentation again from their own perspective, either from scratch or by copy-pasting from other documentation. This approach leads to a serious problem with updating the models and documents. The updating affects only to those very models or documents that are being updated, while those created based on them become obsolete. One example of such a "snap-shot" design approach, how the interviewees called it, was making the assembly process plans or work instructions with Excel and taking several snap shots of the CAD-model, authored, e.g., in CATIA. "The resulting process plan is like a comic book, which is not dynamic, and the usability and efficiency of the plan is greatly affected by the viewpoints from where the snap shots are taken", stated the Mechanics Designer. Immediately when the CAD-model is updated, the assembly process plan or work instruction documentation becomes obsolete, because these two models don't have any integration. However, in reality these obsolete documents continue their existence and in many cases are used as the main information source for part of the design team. During every remake the model gets filtered, because the current phase doesn't need all the information that was needed in the previous development phase, or because the transfer format doesn't support all the data types of the original model.

\section{Effort to collect information manually from multiple sources}

One practical challenge identified during the interviews related to information gathering from multiple dispersed sources to support different engineering analysis, e.g., simulation to evaluate assemblability of the product and cycle time of the assembly process. The R\&D Manager highlighted that in order to perform the simulation, the designer needs information and models from the previous design phases, including the 3D-model of the product as well as of the tools, jigs, and other resources used during the assembly process. These models may be imported into the simulation software in various formats, depending on the tools used. However, often the converted models will be just "dumb" 3D CAD geometry data, and great deal of design information, such as special features or attributes, will be lost.

The designer needs also information about the planned assembly process and sequence, which was in the case company saved into PowerPoint or Excel files. In addition to those, he needs information on various constraints and resource specifications and capabilities, all of which were stored into multiple dispersed documents and formats, e.g., in .doc, .txt, or emails. Hence, the creation of simulation relied on the manual extraction of needed design information from various sources (see Figure 3). The quality of the created simulation was therefore strongly affected by the motivation of the designer to search for this information and, at the same time, by the experience of him to even know what kind of information is needed to create an accurate and reliable simulation, i.e., the result was strongly dependent on the engineer's tacit knowledge, as discussed already earlier.

As a result of the time consuming manual simulation work, the designer got a closed model of the assembly process. From that model, statistics could be exported usually to Excel, resulting in a bunch of fragmented numbers, which didn't have any connection to the original 3D-model of the product. During the manual extraction of design information and format translations the relations between the models and the design domains had been lost. 


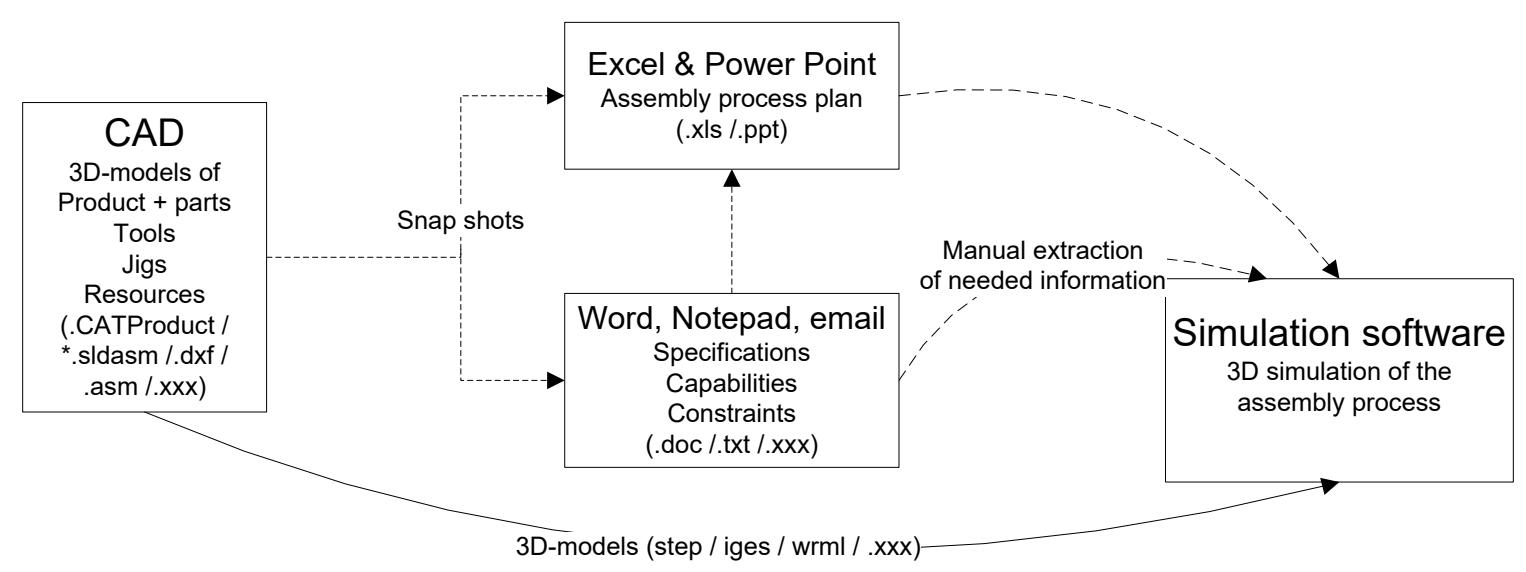

Figure 3: Information flow from product design to assembly process simulation.

\section{Problems with format translations}

In the case company one of the biggest challenges in the information exchange between the company and its sub-contractors related to the use of different CAD-tools which have their own proprietary native formats for defining 3D and 2D geometries, dimensional information, tolerances, and other design information. Even though the sub-contractors didn't fabricate the parts of the product itself, but special tools used in the assembly process, the use of different CAD-systems clearly complicated cooperation requiring time consuming data translations. One sub-contractor representative mentioned: "Previously when we used Solid Works (customer use CATIA), we utilized the Solid Works add-on to translate the model from CATIA to Solid Works format. The process was so slow that we had to leave the computer running all night."

During the case study it was noted that even though the standards for exchanging product information between various systems exist, they were not seen as a sufficient technique to exchange the information. The interviewees criticized that for example the STEP (AP203, AP214) implementation in the used CAD tool was only capable of exchanging simple geometrical data and a lot of information, such as the history data was filtered out during the conversion. Sometimes errors happened during the conversion, leading to exploded, unusable models. Losing the history information was regarded as problematic on both sides, the OEM and the sub-contractor. For instance, the Mechanics Designer stated: "From some sub-contractors, we get the jig designs in STEP format, which cannot convey the history information. It is therefore very cumbersome to compare between the new and old designs."

\section{Discussion}

The goal of this article was to present the challenges one large Finnish multinational company faces with their current knowledge and information management practices and tools during NPI process, and to mirror them against the theoretical findings from literature. The case study suggests that that there are both social and technical aspects that affect to the success of knowledge and information management in companies. The first ones relate to the different individual characteristics, background and motivation, mental and physical distance between the individuals, organizational culture, and work and information processes and practices. Technical aspects relate to the used information systems, the amount and distribution of different information sources and interoperability between the systems. 
In the following sections the results from the interviews are first mirrored against the findings from the knowledge management literature. After that the research and its limitations are discussed, after which the implications of the research are presented.

\section{Mirroring the Findings against Literature}

Both the identified social and technical challenges were very similar to the challenges mentioned in the literature. Only a few slight contradictions were noted and in many cases the literature helped to further explain the empirical findings done during the interviews and discussed in the previous section. The case study, for instance, supported the findings presented in the literature review according to which the organizational knowledge creation is very sensitive to social context, such as the organization of processes (Dyck et al., 2005), timing of activities (Massey \& Montoya-Weiss, 2006), physical proximity of people (McFadyen \& Cannella, 2005) and people's use of technology (Chou \& He, 2004).

According to O'Dell and Grayson (1998), sharing knowledge requires that time is taken away from other responsibilities, which have a higher priority. Therefore, people naturally focus on those tasks which are more beneficial to them (Lubit 2001). This partly explains why the employees in the case organization saw knowledge codification as a redundant task, even though they didn't directly state it that way. Instead they stated that due to the information overload nobody would find or re-use the created documents anyway. Motivation for creating and sharing knowledge is based on the considerations of personal benefit, community related expectations, and normative beliefs (Ardichvili 2008). The employees did not convert their tacit knowledge into explicit (e.g., documents) because there were no rewards for such activities nor punishments for discarding them. Even though Nonaka (1994), as well as, Nonaka and Takeuchi (1995) see that sharing redundant information speeds up the knowledge creation process, the case study suggests that increasing the amount of information to be processed leads to information overload. The interviewees highlighted that due to information overload, it becomes impossible to recognize the relevant information anymore and something critical is often missed.

Misunderstandings in knowledge sharing, transfer, and cooperation can be explained with the diversity of people involved in the NPI projects. Collaboration in the heterogeneous group can be difficult because each profession has its own language, terminology, beliefs, approaches to learning, mechanisms for information exchange, goals, and reward structure (Edmondson \& Nembhard, 2009). Sharing of all forms of knowledge requires a joint language, a commonly understood terminology (Halding-Herrgard, 2000). The more distance the individuals have from each other's practice, the more difficult it is to communicate knowledge they use (Crossan et al., 1999). In the case company it was clearly visible that the persons working, e.g., in the Production Department, had different vocabulary and mental models than those working in R\&D. Therefore, the documents created in one department were not always interpreted as their authors in the other department had intended. On the other hand, with those individuals with whom they had "a common language", communication and understanding each other was reported to be easy and effortless.

When information systems and databases are used in knowledge sharing and transfer, it requires the knowledge to be translated into explicit information. Converting tacit knowledge into explicit information includes explaining one's own experiences and viewpoints in a way that is understandable to others. The reader on the other hand needs to try to understand what the other meant. Polanyi (1969a) called these processes as sense-giving and sense-reading. For instance, when an engineer is observing a function of a new product and then explaining it to his colleagues, first he needs to use cognitive effort to understand the function of the product by himself by observing the product (engineer: sense-reading). The engineer uses his mental models to understand and interact with the system (Ritter et al., 2014). Then he needs to compose a verbal or textual de- 
scription of his experience (engineer: sense-giving). After those actions, the colleague needs to interpret this verbal or textual description by using his own mental models (colleague: sensereading). Based on this, it is easy to understand that the knowledge to be shared of transferred is subject to many misunderstandings during such sense-giving and sense-reading process. Most of the documentation in company's databases did not contain objective explicit knowledge which could be shared with colleagues in an unproblematic way, because it always includes tacit sensereading and sense-giving activities.

As Walsham (2001) stated, personal interaction between individuals in a community with common symbols, such as specialist language and job purpose, facilitates the sense-giving and sensereading processes in a way which supports the knowledge sharing. This was clearly noted in the case company. Physical face-to-face experiences are the key to conversion and transfer of tacit knowledge (Nonaka \& Konno 1998). The face-to-face communication allows immediate feedback, the interaction uses much variety, natural language, and the messages are tailored personally to the recipient (Koskinen, Pihlanto, \& Vanharanta. 2003). Misinterpretation of meanings is less likely than in less close forms of social relations. Furthermore, in the case company, the personal interaction helped to draw the attention of people to the knowledge or information, which otherwise may have been left unnoticed. It was evident that the databases only complement the personal networks of those seeking answers to the problems (as mentioned by Davenport \& Prusak, 1998; Koskinen et al., 2003), and communication is the main mode by which the workers discover what they know and share it with their colleagues (Davenport \& Prusak, 1998).

The problem with collective sense-making, discussed by Walsham (2001), was clearly visible. Because different people tended to use the systems in a different way and with different experience, the information that could be retrieved from the systems was not always consistent and reliable. It was noticed that effective sharing of knowledge and information cannot be facilitated by just saving the information into databases and other information systems. In order to use the tool appropriately, knowledge about the good practice to use that tool needs to be learned. For example, in order to understand what a specific instance in a PDM system means, one needs to understand the purpose of the system, as well as, to know what schemata were used to store the information to the system.

However, in contrary to Walsham's (2001) statement, it was also noted that using computers to support collaboration may also facilitate collective sense-making. Most of the engineering software provides common symbols for different actors, easing the communication. When the actors have a similar understanding of these symbols, the engineering software provides a structured way to communicate information, compared to unstructured documents like Power Point presentations or product specifications written in memo-style Word-documents. However, the software system has to be carefully selected to serve the purpose.

The knowledge management literature often highlights the effect of spatial distance to knowledge sharing. For instance, based on Koskinen et al. (2003) physical proximity enhances tacit knowledge utilization in the project work. The conducted interviews, on the other hand, highlighted personality and chemistry between the individuals over the physical proximity. Also, there was some hesitance to share knowledge or information with the external partners. The case company felt unsecure to share, e.g., product models with their global suppliers. Based on the literature, similar challenges exist in all companies: it is essential to protect proprietary knowledge while, at the same time, encourage contributions to the collective good (Dyer \& Nobeoka, 2000).

The case company acts in a very volatile and rapidly changing field of industry. The literature suggests that when the business environment changes the organizations need to learn to adapt also their routines to the changed circumstances (Jashapara, 2011). However, in the case organization, 
the continuous changes in routines were seen as a problem and the changes affected negatively the information flows and transparency.

Neither the project nor the organizational culture in the case company encouraged knowledge codification or learning from other projects, i.e., knowledge transfer from project to project. The same mistakes were repeated in several consequent projects because there were no organizational mechanisms for the knowledge acquired in one project to be transferred and used by the other projects (see, e.g., Prencipe \& Tell, 2001). This led to the frustrating situation described by the interviewees: even though the problems and errors in the previous product designs were properly documented in a dedicated system, the same design mistakes were repeated over and over again in the next product generations. This indicates that the reports were probably not even read by other teams. The interviews also supported Riege's (2005) argument that ignorance at both ends is one of the biggest knowledge sharing barriers in projects. Neither the knowledge source nor the recipient is too concerned with who requires knowledge or who possesses knowledge.

The case study also supports the idea that many formal knowledge sharing practices in the organizations depend on the information systems offering support on information acquisition, organization, storage, retrieval, search, presentation, distribution, and reproduction (Thierauf 2001). However, the role of technology can be exaggerated and misstated, which causes confusion about what the technology should, can, and cannot do. Furthermore, psychological and cognitive challenges in using IT systems cannot be underestimated. When the systems are unexciting, complex, buggy, or lack cognitive ergonomics, their use can be very unpleasant (Ritter et al., 2014). This will inevitably decrease the motivation to apply the systems, as was witnessed in the case company.

Literature suggests that knowledge sharing in organizations can be managed by two approaches, namely, emergent and engineering (van den Hooff \& Huysman, 2009). In the case company the focus had been on the latter approach. A lot of technological solutions, i.e., different IT systems, servers and databases, had been provided to facilitate the knowledge and information creation and sharing during the NPI process. Unfortunately, it seems that the company had neglected the social aspects and facilitation of the motivation of individuals to use these systems. According to Christensen (2007), the purpose of knowledge sharing is either to create new knowledge by differently combining existing knowledge or to become better at exploiting existing knowledge. In the case company, the goal of knowledge sharing was not clearly thought out nor formulated.

Furthermore, there were technical issues which hindered the information transparency. Depending on the purpose of the design task to be solved, the modelled entity is viewed from different viewpoints or aspects (Whitney, 2004). For example, if one wants to analyze the manufacturability of a product he is interested in different aspects from the one who is analyzing the functionality or appearance of the product. Therefore, during the product development process, vast amounts of different plans, models, and other documentation is created with different systems, in different formats. Multiple distributed IT systems caused several technical challenges in the case organization, the most important ones being the lack of linked information, as well as filtering and errors happening during format translations, which caused a lot of manual re-writing and searching for information. These challenges related to data format translations and interoperability issues between different systems are very common in companies and often mentioned in the literature (Lanz, 2010; Ray \& Jones, 2006).

\section{Evaluation of the Research}

The selected research method, namely, interview study, set some limitations for the case study. The interviewees' personality and attitudes affect greatly to the research results. Each individual is different and has a different way to communicate and express herself. Also, the position of the 
interviewed person in the company affects the viewpoint he gives to the subject. The interviewed persons answered to the questions not only from their own perspective (what they know for sure), but how they see the whole and think what the others are doing. Therefore, the results were strongly affected by the interviewees' assumptions, interpretations, and feelings.

The validity of the results can be questioned because the authors didn't get access to the actual information systems of the target company. The analysis of the information flows had to be based on very fractured and small pieces of information gathered from the interviewees. In order to get more comprehensive and reliable results, more people could have been interviewed. On the other hand, most important issues were identified and there were no contradictions between the interview results and the opinions of the workshop participants. The purpose of the interviews was not to collect quantitative data, but to highlight the current issues that hinder efficient information and knowledge management, information flows, and transparency in the case company.

Even though the interviews observed the knowledge and information management on three levels, namely, human, system, and format, the questions of the interviews were very pragmatic concentrating mainly on the usage of the IT systems and information flows, neglecting the social and behavioral aspects. Thanks to the flexibility of open-ended interview methodology, the interview brought out issues relating to these aspects as well. This lead to the extension of the literature review, which allowed the authors to analyze the results from a wider socio-technical perspective.

As the study was a single case study, the results are to be used for interpreting how and why things happened in one specific company (Yin, 2009). Although similar challenges are very common in industrial world, the results cannot be generalized as such. Especially the large size of the case company and its operations in multiple locations worldwide increases the complexity of the information and knowledge management and puts even more importance on the digital information flow compared to, e.g., small and medium size companies, which form the majority of the Finnish and European manufacturing companies.

\section{Implications of the Research}

Some of the knowledge and information management challenges identified in the case company can be fixed, but many of them are something which just need to be lived with and acknowledged. For instance, the human behavior, personality, and cognitive capabilities are difficult to change, but can be best exploited by user-centric human-friendly design of the workplaces, processes, and technologies.

The results of this study indicate that the information processes, especially in large organizations, should be carefully defined and distributed, and the technical solutions should seamlessly support these processes. In the studied organization, the unclear processes led to a situation in which it was impossible for different teams and individuals to know where the needed information is, what kind of information even exits and who needs the information they could provide. Therefore, the same documentation was created over and over again, from different perspectives, but maybe with only slight differences.

When selecting or developing new information and knowledge sharing systems and practices, specific attention should be placed on the usability of the system or practice. Principles of humancentric design should be utilized to ensure the human behavior and cognitive capabilities are taken into account (Ritter et al. 2014). For those carefully selected IT systems, a proper training to the users should be provided. The management should ensure that these systems are used consistently throughout the organization, otherwise the information in the system cannot be trusted. It can be fatal to make decisions based on inaccurate information. Good usability will increase the chances that people use the system correctly and that they feel motivated towards using it. The 
whole organization should be committed to following the defined processes carefully. This would increase the transparency of operations and information throughout the organization and also help to minimize the information overload.

There is a significant urge within companies to turn tacit knowledge of individuals into explicit and useable by many. However, it is not always well defined what are the targets of this codification. In the studied organization, motivation to create explicit documentation was low, due to the low re-use of the documented information. This affected to the quality of the created documents, and, furthermore, their re-usability. One could ask: what is the point in investing in time consuming thinking, formulation and writing process to convert the tacit knowledge explicit, if that knowledge is not used by many? Therefore, it would be important to identify the critical knowledge, which needs to be made explicit, rather than codifying everything.

The studied organization represented a very dynamic environment, where the information systems and practices are constantly changing. In such environment the integration of various IT systems and models used during the product's lifecycle becomes very challenging. Ontologies could be applied to support interoperability between different design systems, by providing the common vocabulary and semantics between different concepts. The different IT systems can map their information structure with the common ontology and this way the different systems can utilize and contribute to the same knowledge base. If the information would always be retrieved from a common knowledge base and read back there, the designers could always work with the newest information and redundant models with obsolete information would be eliminated. Furthermore, semantic knowledge management systems utilizing ontologies enable linked information, which can ease up the finding of correct information. They can automate the reasoning traditionally done by humans based on the defined relations between different concepts and models, and this way reduces the need for human's tacit knowing and time consuming searching.

\section{Conclusions}

This article presented the results from a study conducted in a single Finnish multinational company related to its knowledge and information management challenges during new product introduction process. Furthermore, a comparison of the findings against relevant literature was presented. The case study was conducted by interviewing relevant persons in different positions in the company. Aside from the limitations of using interviews as a research methodology, comparing different viewpoints given by different individuals in the same factual connection led to deeper understanding of the research subject. It emphasized the importance of human social and behavioral aspects when studying organizational knowledge and information management. During the research, it became evident that knowledge and information management cannot be viewed solely from IT system or information flows' perspective. It is a complex socio-technical ensemble, which benefits from a holistic viewpoint.

The main contribution of this article was to exemplify how the knowledge and information management challenges discussed in theoretical literature manifest themselves in the operations of a real industrial company. From practical perspective it highlighted the everyday challenges in the studied company and provided focus points for the management. The management will be better able to provide environment for effective knowledge and information management after they have analyzed the social and technical challenges illustrated by the results.

Based on the practical case study and literature review, a couple of issues causing the main challenges in knowledge and information management in large and distributed organizations could be identified. First of all, there are the challenges related to human behavior, individual characteristics and capabilities, different backgrounds, and professional vocabulary, which affect to how the individuals communicate and are able to share knowledge with each other. Moreover, in order to 
make the individuals' knowledge available for many, it needs to be saved to company IT systems. This requires that the tacit knowledge is codified into explicit form. This is a time-consuming process, and the resulting information may be interpreted differently than originally intended, due to individuals' different mental models. In addition, due to weak interoperability, the IT systems used to store and handle explicit information are usually not able to share it with other IT systems. This leads to multiple dispersed models, containing a lot of redundant information, which cause troubles when the information needs to be updated. Furthermore, traditional IT systems are not able to capture the design intent nor knowledge, only data and information can be stored. They don't support linked information, such as Semantic Web, and thus don't allow intelligent reasoning to be performed based on the stored information to infer new knowledge.

A few starting points for solving these challenges were presented in the discussion section. The case company will utilize the findings in their internal development activities, while the authors will focus their future work on studying similar issues in small and medium sized companies, and comparing how the issues differ between large and distributed organizations and smaller companies having activities in only one or few locations.

\section{Acknowledgements}

The authors would like to thank the case company and all the individuals who participated in the interviews and workshops during the study. Special thanks are due to Tekes, the Finnish Funding Agency for Innovation, for funding the practical part of the research. The authors would also like to thank the reviewers of the article for their valuable comments.

\section{References}

Alavi, M., \& Leidner, D. E. (2001). Knowledge management and knowledge management systems: Conceptual foundations and research issues. MIS Quarterly, 25(1), 107-136.

Ardichvili, A. (2008). Learning and knowledge sharing in virtual communities of practice: Motivators, barriers, and enablers. Advances in Developing Human Resources, 10(4), 541-554.

Avgoustinov, N. (2007). Modelling in mechanical engineering and mechatronics: Towards autonomous intelligent software models. London: Springer Verlag.

Awad, E. M., \& Ghaziri, H. (2004). Knowledge management (1st ed.). New Jersey: Prentice Hall.

Bartol, K. M., \& Srivastava, A. (2002). Encouraging knowledge sharing: The role of organizational reward systems. Journal of Leadership \& Organizational Studies, 9(1), 64-76.

Bierly, P. E., Kessler, E. H., \& Christensen, E. W. (2000). Organizational learning, knowledge and wisdom. Journal of Organizational Change Management, 13(6), 595-618.

Bratianu, C., \& Orzea, I. (2010). Tacit knowledge sharing in organizational knowledge dynamics. Proceedings of the European Conference on Intellectual Capital, 11(2), 107-114.

Chou, S.-W., \& He, M.-Y. (2004). Knowledge management: The distinctive roles of knowledge assets in facilitating knowledge creation. Journal of Information Science, 30(2), 146-164.

Christensen, P .H. (2007). Knowledge sharing: Moving away from the obsession with best practices. Journal of Knowledge Management, 11(1), 36-47.

Crossan, M. M., Lane, H. W., \& White, R. E. (1999). An organizational learning framework: From intuition to institution. Academy of Management Review, 24(3), 522-537.

Davenport, T. H., \& Prusak, L. (1998). Working knowledge: How organizations manage what they know. Boston: Harvard Business School Press.

Dyck, B., Starke, F. A., Mischke, G. A., \& Mauws, M. (2005). Learning to build a car: An empirical investigation of organizational learning. Journal of Management Studies, 42(2), 387-416. 
Dyer, J. H., \& Nobeoka, K. (2000). Creating and managing a high-performance knowledge-sharing network: The Toyota case. Strategic Management Journal, 21(3), 345-382.

Edmondson, A. C., \& Nembhard, I. M. (2009). Product development and learning in project teams: The challenges are the benefits. Journal of Product Innovation Management, 26(2), 123-138.

Haldin-Herrgard, T. (2000). Difficulties in diffusion of tacit knowledge in organizations. Journal of Intellectual Capital, 1(4), 357-365.

Hepp, M., Leenheer, P. De, de Moor, A., \& Sure, Y. (Eds.). (2007). Ontology management: Semantic web, semantic web services, and business applications. New York: Springer.

Hildreth, P. M., \& Kimble, C. (2002). The duality of knowledge. Information Research, 8(1), paper 142.

Jashapara, A. (2011). Knowledge management: An integrated approach (2nd ed). Harlow: Pearson Education Limited.

Jeon, J. (2009). Success factors for a lessons-learned system in a construction organization. Cost Engineering, 51(5), 13-20.

Kogut, B., \& Zander, U. (1992). Knowledge of the firm, combinative capabilities, and the replication of technology. Organization Science, 3(3), 383-397.

Koskinen, K. U., Pihlanto, P., \& Vanharanta, H. (2003). Tacit knowledge acquisition and sharing in a project work context. International Journal of Project Management, 21(4), 281-290.

Lam, A. (2000). Tacit knowledge, organizational learning and societal institutions: An integrated framework. Organization Studies, 21(3), 487-513.

Lanz, M. (2010). Logical and semantic foundations of knowledge representation for assembly and manufacturing processes. PhD Thesis. Tampere: Tampere University of Technology.

Lubit, R. (2001). Tacit knowledge and knowledge management: The keys to sustainable competitive advantage. Organizational Dynamics, 29(3), 164-178.

Massey, A. P., \& Montoya-Weiss, M. M. (2006). Unraveling the temporal fabric of knowledge conversion: A model of media selection and use. MIS Quarterly, 30(1), 99-114.

McFadyen, M. A., \& Cannella, A. A. J. (2005). Knowledge creation and the location of university research scientists' interpersonal exchange relations: Within and beyond the university. Strategic Organization, $3(2), 131-155$.

Newell, S., \& Edelman, L. F. (2008). Developing a dynamic project learning and cross-project learning capability: Synthesizing two perspectives. Information Systems Journal, 18(6), 567-591.

Nissen, M.E. (2002). An extended model of knowledge-flow dynamics. Communications of the Association for Information Systems, 8(18), 166-251.

Nonaka, I. (1994). A dynamic theory of organizational knowledge creation. Organization Science, 5(1), $14-37$.

Nonaka, I., \& Konno, N. (1998). The concept of 'Ba: Building a foundation for knowledge creation. California Management Review, 40(4), 40-54.

Nonaka, I., \& Lewin, A.Y. (1994). Dynamic theory knowledge of organizational creation, Organization Science, 5(1), 14-37.

Nonaka, I., \& Takeuchi, H. (1995). The knowledge-creating company: How Japanese companies create the dynamics of innovation. New York: Oxford University Press.

Nonaka, I., Toyama, R., \& Konno, N. (2000). SECI, Ba and leadership: A unified model of dynamic knowledge creation. Long Range Planning, 33(1), 5-34.

Nonaka, I., \& von Krogh, G. (2009). Tacit knowledge and knowledge conversion: Controversy and advancement in organizational knowledge creation theory. Organization Science, 20(3), 635-652. 
O'Dell, C., \& Grayson, C. (1998). If only we knew what we know: Identification and transfer of internal best practices. California Management Review, 40(3), 143-174.

Polanyi, M. (1966). The tacit dimension. Chicago: University of Chicago Press.

Polanyi, M. (1969a). On body and mind. New Scholaticism, 43(2), 195-204.

Polanyi, M. (1969b). Knowing and being: Essays. Chicago: University of Chicago Press.

Prencipe, A., \& Tell, F. (2001). Inter-project learning: Processes and outcomes of knowledge codification in project-based firms. Research Policy, 30(9), 1373-1394.

Ray, S. R., \& Jones, A. T. (2006). Manufacturing interoperability. Journal of Intelligent Manufacturing, 17(6), 681-688.

Riege, A. (2005). Three-dozen knowledge-sharing barriers managers must consider. Journal of Knowledge Management, 9(3), 18-35.

Ritter, F. E., Baxter, G. D., \& Churchill, E. F. (2014). Foundations for designing user-centered systems. London: Springer.

Smith, E. A. (2001). The role of tacit and explicit knowledge in the workplace. Journal of Knowledge Management, 5(4), 311-321.

Smith, H. A., McKeen, J. D., \& Singh, S. (2007). Tacit knowledge transfer: Making it happen. Journal of Information Science \& Technology, 4(2), 23-44.

Staab, S., \& Studer, R. (Eds.). (2009). Handbook on ontologies. Berlin: Springer.

Subashini, R. (2010). Tacit knowledge: The ultimate essence of an organization. Advances in Management, $3(8), 36-39$.

Thierauf, R. J. (2001). Effective business intelligence systems. Westport: Greenwood Publishing Group.

Tuomi, I. (1999a). Corporate knowledge: Theory and practice of intelligent organizations. Helsinki: Metaxis.

Tuomi, I. (1999b). Data is more than knowledge: Implications of the reversed knowledge hierarchy for knowledge management and organizational memory. In Proceedings of the 32nd Annual Hawaii International Conference on Systems Sciences, Honolulu, 5-8 Jan, 1999.

van den Hooff, B., \& Huysman, M. (2009). Managing knowledge sharing: Emergent and engineering approaches. Information \& Management, 46(1), 1-8.

von Krogh, G. (1998). Care in knowledge creation. California Management Review, 40(3), 133-153.

von Krogh, G., Ichijo, K., \& Nonaka, I. (2000). Enabling knowledge creation: How to unlock the mystery of tacit knowledge and release the power of innovation. Oxford: Oxford University Press.

Walsham, G. (2001). Knowledge management: The benefits and limitations of computer systems. European Management Journal, 19(6), 599-608.

Whitney, D. E. (2004). Mechanical assemblies: Their design, manufacture, and role in product development. Oxford: Oxford University Press.

Yin. R. (2009). Case study research: Design and methods. (4th ed.) Thousand Oaks: Sage Publications. 

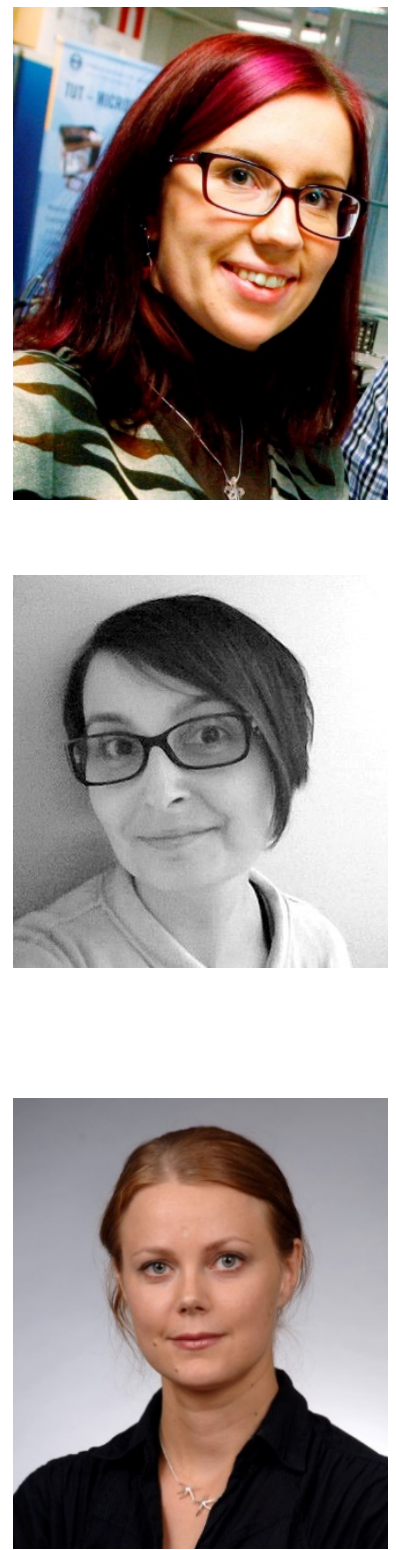

\section{Biographies}

Dr. Eeva Järvenpää works as a Post-doctoral Researcher at Tampere University of Technology, Department of Mechanical Engineering and Industrial Systems. She has been working at TUT since 2006 in several international and national research projects relating to knowledge and information management, manufacturing system design, digital manufacturing, manufacturing operations management systems, formal information models, information flow analysis, and sustainable manufacturing. She is currently working as a project manager in Horizon 2020 -project called ReCaM, where she is involved in the development of formal information models supporting rapid reconfiguration of production systems.

Dr. Miia-Johanna Kopra has a Ph.D. in Business Information Management (2012). She currently works as a Post-doctoral Researcher at Tampere University of Technology, Department of Mechanical Engineering and Industrial Systems. Prior joining the academia, she worked for 15 years in various positions related to the product development projects in the ICT industry. Dr. Kopra's primary research areas are product development, operational development, and organizational learning.

Associate Professor Minna Lanz works at the Dept. of Mechanical Engineering and Industrial Systems as associate professor for Production Engineering and Manufacturing and Production Automation research area leader. Her research area touches formal knowledge representations, semantic information modelling, engineering knowledge management, LEAN, open and complex production systems, systems engineering, and holonic manufacturing systems (in heavy metal/ discreet part manufacturing). Currently running projects concern Lean Manufacturing Execution Systems (LeanMES) and socio-technical sustainability in the field of Mechanical Engineering and Manufacturing Industry. 